\title{
319 直交異方性不均質長方形板の熱弾性解析 \\ Thermoelastic Analysis of an Orthotropic, Nonhomogeneous Rectangular Plate
}

\author{
正 谷川 義信 (阪府大工) \\ $O$ 学 黄 得天 (阪府大院)
}

\section{Yoshinobu TANIGAWA, Osaka Prefecture University, 1-1, \\ Gakuen-cho, Sakai, Osaka}

Tokuten KOU, Graduate Student, Osaka Prefecture University

Key Words : Orthotropic material, Nonhomogeneous material, Rectangular plate,

Thermal deformation, Thermal stress

\section{1. 緒 言}

本研究は、面内方向に関して直交異方性をもち、更に板厚 方向に関して不均質な材料物性を持つ長方形板を解析モデ ルとして取り上げ、非一様な加熱を受ける場合の熱弾性挙動 の理論解析及び数值シミュレーションを行ったものである。 特に、厚さ方向に関する不均質性が熱弾性解（たわみ、モー メントなど）に及ぼす影響について検討した。

\section{2. 解析モデル}

図 1 に示すように、 $\mathrm{x}$ 方向の長さが $\mathrm{a}, \mathrm{y}$ 方向の長さが $\mathrm{b}$ 、 厚さ hの長方形板を考える。簡単化のため、 $\mathrm{x}$ 軸、 $\mathrm{y}$ 軸に関 して対称な問題を想定し、板の上面と下面から非一様な加熱 を受ける場合の定常問題について考える。また、直交異方性 の主軸は、 $\mathrm{x}$ 軸、 $\mathrm{y}$ 軸と一致している場合を想定する。
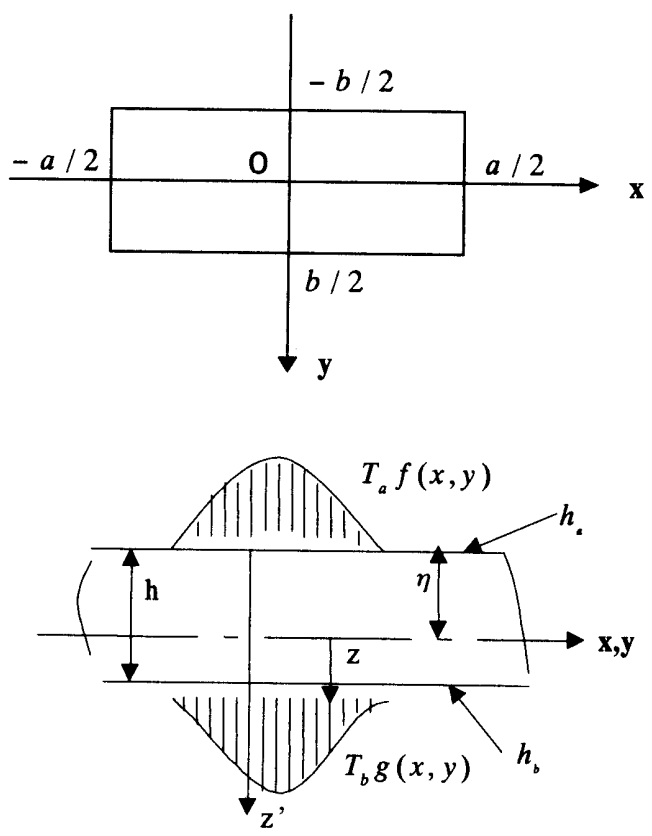

Fig.1 Analytical Model

\section{3. 解析方法}

3. 1 温度解析 直交異方性不均質長方形板の三次元定常熱 伝導の方程式は、内部熱発生のない場合、次式で与えられる。

$$
\frac{\partial}{\partial x}\left\{\lambda_{x}(z) \frac{\partial T}{\partial x}\right\}+\frac{\partial}{\partial y}\left\{\lambda_{y}(z) \frac{\partial T}{\partial y}\right\}+\frac{\partial}{\partial z}\left\{\lambda_{z}(z) \frac{\partial T}{\partial z}\right\}=0
$$

ここで $\lambda_{x}, \lambda_{y}, \lambda_{z}$ はそれぞれ $\mathrm{x}, \mathrm{y}, \mathrm{z}$ 方向に関する熱伝導率、 $\mathrm{T}$ は温度変化、 $z$ は図 1 に示すように中立面から測った板厚方 向座標である。加熱条件として、板の上面 $\left(\mathrm{z}^{\prime}=0\right)$ が $T_{a} f(x, y)$ 、 下面 $\left(\mathrm{z}^{\prime}=\mathrm{h}\right)$ が $T_{b} g(x, y)$ の媒体により相対熱伝導率 $h_{a}, h_{b}$ で加 熱される場合を想定する。更に簡単化のため、板の周辺境界 上 $(x= \pm a / 2, y= \pm b / 2)$ は零度に保持されると仮定する。こ の時、温度境界条件は

$$
\begin{aligned}
& z^{\prime}=0: \quad-\frac{\partial T}{\partial z^{\prime}}=h_{a}\left[T_{a} f(x, y)-T\right] \\
& z^{\prime}=h: \frac{\partial T}{\partial z^{\prime}}=h_{b}\left[T_{b} g(x, y)-T\right] \\
& x= \pm a / 2 ; T=0, y= \pm b / 2 ; T=0 \\
& \text { ただし } \\
& z=z^{\prime}-\eta
\end{aligned}
$$

次に、 $\mathrm{x}, \mathrm{y}, \mathrm{z}$ 方向に関する熱伝導率の板厚方向に関する不均質 特性として、次式のように同じ不均質特性を持つと仮定する。

$$
\left.\begin{array}{l}
\lambda_{x}\left(z^{\prime}\right)=\lambda_{x 0}\left(1+z^{\prime} / h\right)^{r}, \lambda_{y}\left(z^{\prime}\right)=\lambda_{y 0}\left(1+z^{\prime} / h\right)^{r}, \\
\lambda_{z}\left(z^{\prime}\right)=\lambda_{z 0}\left(1+z^{\prime} / h\right)^{r}
\end{array}\right\}
$$

ここで、r は任意の不均質パラメータである。式(5)を式(1) に代入し解析を行えば、境界条件式(3)を満足する温度解の無 次元表示は次式となる。

$\bar{T}-\sum_{m, n}^{\infty} \sum_{n=0 d d}^{\infty}\left\{A_{m n} \bar{z}^{v} I_{v}\left(\beta_{m n} \bar{z}\right)+B_{m n} \bar{z}^{v} \mathrm{~K}_{v}\left(\beta_{m n} \bar{z}\right)\right\} \cos m \pi \bar{x} \cos n \pi \bar{y}(6)$

上式において、 $A_{m n}, B_{m n}$ は境界条件(2)より決定される未定 定数である。また、導入した無次元量は以下の通りである。

$$
\begin{aligned}
& \bar{x}-\frac{x}{a}, \bar{y}=\frac{y}{b}, \bar{z}=\frac{z}{h},\left(\bar{T}, \bar{T}_{a}, \bar{T}_{b}\right)=\left(T, T_{a}, T_{b}\right) / T_{0} \\
& \left(H_{a}, H_{b}\right)=\left(h_{a}, h_{b}\right) \times h,\left(\bar{\lambda}_{x 0}, \bar{\lambda}_{y 0}\right)=\left(\lambda_{x 0}, \lambda_{y 0}\right) / \lambda_{z 0} \\
& (\bar{a}, \bar{b})=(a, b) / h
\end{aligned}
$$

\section{2 熱弹性解析 $\mathrm{x}, \mathrm{y}$ 方向の変位 $u^{\prime}, v^{\prime}$ は}

$$
u^{\prime}=u-z \partial \omega / \partial x, v^{\prime}=v-z \partial \omega / \partial y
$$

である。ここで、 $u, v$ は中立面 $(\mathrm{z}=0)$ での $\mathrm{x}, \mathrm{y}$ 方向の変位成分、 $\omega$ は $\mathrm{z}$ 方向のたわみである。また、ひずみ成分は

$$
\varepsilon_{x x}=\frac{\partial u^{\prime}}{\partial x}, \varepsilon_{y y}=\frac{\partial v^{\prime}}{\partial y}, \varepsilon_{x y}=\frac{1}{2}\left(\frac{\partial u^{\prime}}{\partial y}+\frac{\partial v^{\prime}}{\partial x}\right)
$$

応力一ひずみ関係式は

$$
\left.\begin{array}{l}
\varepsilon_{x x}=\frac{1}{E_{x}}\left\{\sigma_{x x}-v_{x y} \sigma_{y y}\right\}+\alpha_{x} T \\
\varepsilon_{y y}=\frac{1}{E_{y}}\left\{\sigma_{y y}-v_{y x} \sigma_{x x}\right\}+\alpha_{y} T \\
\varepsilon_{x y}=\frac{1}{2 G_{x y}} \sigma_{x y}
\end{array}\right\}
$$

式(8) (10)より、応力成分 $\sigma_{x x}, \sigma_{y y}, \sigma_{x y}$ を定式化することがで きる(詳細省略)。更に、中立軸 $(\mathrm{z}=0)$ 周りの軸力、モ一メン トを次式で定義する。

$$
\left.\begin{array}{l}
N_{x}=\int \sigma_{x x} d z, N_{y}=\int \sigma_{y y} d z, N_{x y}=\int \sigma_{x y} d z \\
M_{x}=\int \sigma_{x x} z d z, M_{y}=\int \sigma_{y y} z d z, M_{x y}=-\int \sigma_{x y} z d z
\end{array}\right\}
$$


式(10)において、物性值 $E_{x}, E_{y}, G_{x y}, \alpha_{x}, \alpha_{y}, v_{x y}, v_{y x}$ は、すべて $\mathrm{Z}$ 方向に関する不均質特性を有するが、簡単化のため $v_{x y}, v_{y x}$ は一定值であると仮定する。ここで、 $E_{x}, G_{x y}$ に対し て、次式の不均質特性を仮定する。

$$
E_{x}\left(z^{\prime}\right)=E_{x 0}\left(1+\frac{z^{\prime}}{h}\right)^{m^{\prime}}, G_{x y}\left(z^{\prime}\right)=G_{x y 0}\left(1+\frac{z^{\prime}}{h}\right)^{m^{\prime}}
$$

この時、 $E_{y}\left(z^{\prime}\right)$ は応力一ひずみ関係の相反性より

$$
E_{y}\left(z^{\prime}\right)=\frac{v_{y x}}{v_{x y}} E_{x 0}\left(1+\frac{z^{\prime}}{h}\right)^{m^{\prime}}
$$

更に、平板に対するモーメントと力のつりあい式を考虑すれ ば、たわみ $\omega$ に関する方程式は、横荷重が作用しない場合、

$$
\begin{aligned}
& \frac{\partial^{4} \omega}{\partial x^{4}}+\frac{v_{y x}}{v_{x y}} \frac{\partial^{4} \omega}{\partial y^{4}}+\left\{2 v_{y x}+4\left(1-v_{x y} v_{y x}\right) \frac{G_{x y 0}}{E_{x 0}}\right\} \frac{\partial^{4} \omega}{\partial x^{2} \partial y^{2}} \\
& =-\frac{1}{D_{3}}\left[\frac{\partial^{2} M_{x T}}{\partial x^{2}}+\frac{\partial^{2} M_{y T}}{\partial y^{2}}\right]
\end{aligned}
$$

上式において

$$
\begin{aligned}
& M_{x T}=\frac{1}{1-v_{x y} v_{y x}} \int E_{x}(z)\left\{\alpha_{x}(z)+v_{y x} \alpha_{y}(z)\right\} T(x, y, z) z d z \\
& \left.M_{y T}=\frac{1}{1-v_{x y} v_{y x}} \frac{v_{y x}}{v_{x y}} \int E_{x}(z)\left\{\alpha_{y}(z)+v_{x y} \alpha_{x}(z)\right\} T(x, y, z) z d z\right\}(15) \\
& D_{3}=\frac{1}{1-v_{x y} v_{y x}} \int E_{x}(z) z^{2} d z
\end{aligned}
$$

$$
\eta=\int_{0}^{k} E_{x}\left(z^{\prime}\right) z^{\prime} d z^{\prime} / \int_{0}^{k} E_{x}\left(z^{\prime}\right) d z^{\prime}
$$

まず、板の支持条件として、全周単純支持の場合を考える。 この時、境界条件は

$$
\left.\begin{array}{l}
x= \pm a / 2 ; \omega=0, M_{x}=0 \\
y= \pm b / 2 ; \omega=0, M_{y}=0
\end{array}\right\}
$$

式(3)の温度境界条件を考慮すると

$x= \pm a / 2 ; M_{x T}=0, y= \pm b / 2 ; M_{y T}=0$

となるので、全周単純支持の場合の境界条件は

$$
\left.\begin{array}{l}
x= \pm a / 2 ; \omega=\frac{\partial^{2} \omega}{\partial x^{2}}=0 \\
y= \pm b / 2 ; \omega=\frac{\partial^{2} \omega}{\partial y^{2}}=0
\end{array}\right\}
$$

ここで

$$
\omega=\sum_{m, n}^{\infty} \sum_{n=0 d d}^{\infty} \omega_{m n} \cos m \pi \bar{x} \cos n \pi \bar{y}
$$

とおき、式(21)を基礎式(14)に代入するとたわみ $\omega$ が求めら れる(詳細省略)。

また、他の力学的条件の場合、例えば一対辺固定/他対辺単
純支持、および全周単純支持の場合に対する熱弾性解は、式 (21)で得られたたわみ $\omega に よ り$ 生じる周辺上の $\partial \omega / \partial n$ を零 とする様に等温弾性解を重数合わせることにより求められ る。

\section{4. 数值計算例}

得られた解析解をもとに数値計算を遂行した。得られた結 果の一部として、図 2 に温度分布、図 3 にたわみの分布を示 す。数值計算に用いた数值パラメータは以下の通りである。

$$
\left.\begin{array}{l}
f(\bar{x}, \bar{y})=H\left(\bar{x}_{0}-|\bar{x}|\right) H\left(\bar{y}_{0}-|\bar{y}|\right), \bar{x}_{0}=\bar{y}_{0}=1 / 4 \\
g(\bar{x}, \bar{y})=0, \bar{T}_{a}=1, \bar{T}_{b}=0, \bar{\lambda}_{x 0}=1.0, \bar{\lambda}_{y 0}=2.0 \\
\bar{a}=10, \bar{b}=10, H_{a}=1.0, H_{b}=1.0, r=-1,0,1 \\
m^{\prime}=1.0, v_{x y}=0.3, v_{y x}=0.3, G_{x y 0} / E_{x 0}=0.4 \\
\alpha_{x}(z)=\alpha_{x 0} \bar{z}, \alpha_{y}(z)=0.5 \alpha_{x 0} \bar{z}
\end{array}\right\}
$$

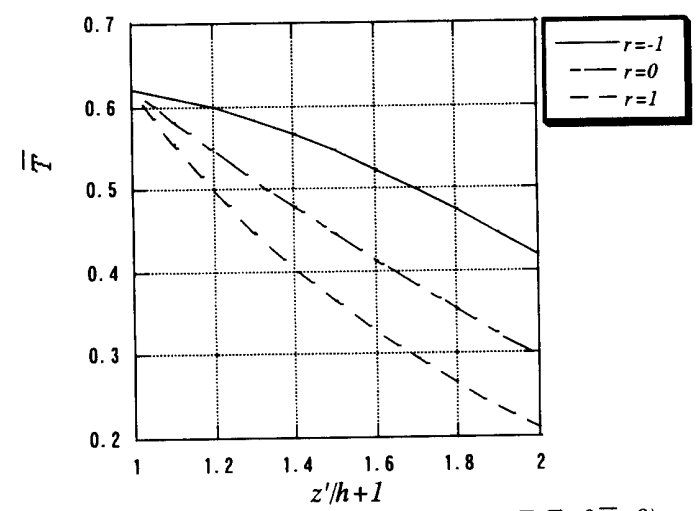

Fig.2 Distribution of Temperature $T(\bar{x}=0, \bar{y}=0)$

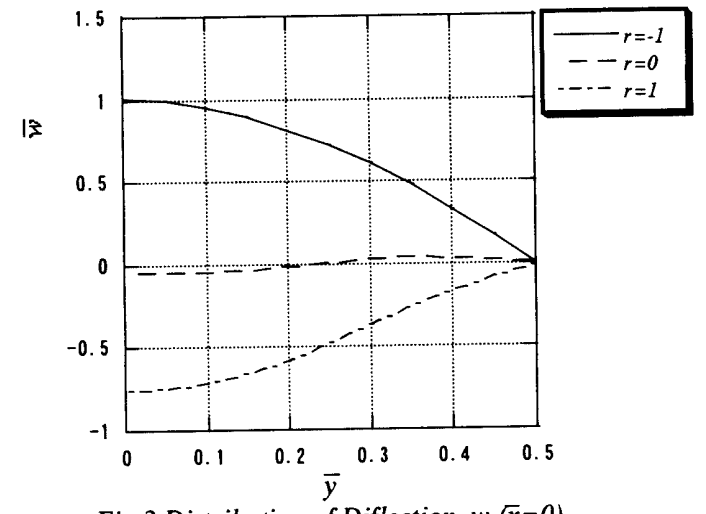

Fig. 3 Distribution of Diflection $w(\bar{x}=0)$

\section{参考文部}

(1) H.S.Carslaw and J.C.Jaeger, Conduction of Heat in Solids, 2nd edition, 1959, Oxford University Press.

（2）菅野他 3 名、直交異方性不均質板の熱応力解析、機論、 A、 57 巻 540 号(1991), 1759 1767. 